\title{
Recompilando o Futuro: o Pensamento Computacional como Parte do Processo de Ressocialização de Detentos
}

\author{
Fábio Ventorim Siqueira, Márcia Gonçalves de Oliveira \\ Instituto Federal do Espírito Santo \\ fabioguiu2014@gmail.com, clickmarcia@gmail.com
}

\begin{abstract}
The Brazilian Criminal Enforcement Law provides that prisoners have a guaranteed right to educational assistance, however, less than $11 \%$ of this population is involved in some educational activity. Here, we show that the estimate for cases of criminal recidivism among prisoners in Brazil is frightening, but there is considerable reduction when the prisoners is involved in some educational activity. This extension project, expected to still apply in 2019, seeks contribute to the process of resocialization of those individuals who are in deprivation of liberty, through the course Recompiling the Future, which aims to develop computational thinking, through the Scratch tool, in people who are in deprivation of freedom.
\end{abstract}

Resumo. A Lei de Execução Penal brasileira prevê que a pessoa privada de liberdade tem direito garantido à assistência educacional, porém, menos de $11 \%$ dessa população está envolvida em alguma atividade educacional. Aqui, mostramos que a estimativa para os casos de reincidência criminal entre os presos no Brasil é assustadora, porém, existe uma redução considerável quando o apenado está envolvido em alguma atividade educacional. Este projeto de extensão, previsto para ser aplicado ainda em 2019, busca, portanto, contribuir com o processo de ressocialização desses indivíduos que encontram-se em privação de liberdade, através do curso Recompilando o Futuro, que visa desenvolver o pensamento computacional, por meio da ferramenta Scratch, em pessoas que encontram-se em privação de liberdade.

\section{Introdução}

O sistema prisional brasileiro enfrenta grande dificuldade para promover a ressocialização das pessoas que se encontram em privação de liberdade. Por todo o país, é possível observar um perigoso processo de deterioração do ambiente carcerário, caracterizado por cadeias superlotadas, com péssimas condições de higiene e habitação.

Segundo o último Levantamento Nacional de Informações Penitenciárias (Infopen)1, publicado em dezembro/2017, o Brasil é o terceiro país com maior número de pessoas presas, chegando a 726.354 internos em junho de 2017, atrás apenas de

1 Relatório Infopen. Disponível em: <http://depen.gov.br/DEPEN/depen/sisdepen/infopen/relatorios-sinteticos/infopen-jun-2017-rev12072019-0721.pdf]>. Acesso: 01 jun. 2019. 
Estados Unidos e China. Considerando que o número de vagas neste período era de 423.242, são quase dois presos para cada vaga. E esse quadro pode piorar consideravelmente, já que uma pesquisa realizada em 2018 pelo Conselho Nacional de Justiça (CNJ) mostrou que existem 143.967 mandados de prisão em aberto no país2, ou seja, pessoas que deveriam estar detidas, mas que estão em liberdade pelos mais diversos fatores.

Ao contrário do senso comum, que acredita ser elevado o número de atentados contra a vida praticados por esses indivíduos, o Infopen mostra que a maioria dos crimes cometidos estão relacionados ao tráfico de drogas $(29 \%)$ e roubos/furtos $(46 \%)$, sendo o homicídio responsável por apenas $12 \%$ das detenções. Estes números nos levam a refletir também até que ponto a falta de oportunidade de uma educação adequada pode ter contribuído para a condição atual de privação de liberdade da maioria dessas pessoas, principalmente quando verificamos nesse levantamento que $64 \%$ da população carcerária brasileira possui, no máximo, o ensino fundamental completo. Enquanto as pessoas com ensino superior completo, não chegam a computar $1 \%$ dos internos.

De acordo com a Lei de Execução Penal (Lei n ${ }^{0} 7.210$, de 11 de julho de 1984), como forma de reintegração da população prisional à sociedade, a pessoa privada de liberdade tem direito garantido à assistência educacional, que deve ser oferecido pelo Estado na forma de instrução escolar e formação profissional. Porém, segundo consta no último relatório do Infopen, menos de $11 \%$ da população prisional no Brasil está envolvida em algum tipo de atividade educacional.

Com o objetivo de promover a educação profissional às pessoas que se encontram em privação de liberdade, desenvolvemos o curso Recompilando o Futuro. Trata-se de um projeto de extensão que visa trabalhar o pensamento computacional, utilizando a ferramenta Scratch, em pessoas que se encontram privadas de liberdade. Desta forma, buscamos apresentar também uma nova oportunidade profissional para estes indivíduos, o que poderá contribuir diretamente em seu processo de ressocialização.

A preocupação em capacitar pessoas com perfil tecnológico encontra respaldo nos números apresentados pela Associação Brasileira das Empresas de Tecnologia da Informação e Comunicação (Brasscom), que reúne setenta associados dentre as maiores e mais significativas empresas do setor de TIC, como Amazon.com, Dell EMC, Linux, Microsoft, Oracle e SAP. Afinal, seu relatório setorial3, apresentado em maio de 2019, mostra que no último ano foram contabilizados mais de 845 mil empregos e existe a expectativa para um investimento de 345,5 bilhões de reais entre os anos de 2019 e 2022, fazendo com que a previsão de demanda profissional nessa área seja estimada em 420 mil profissionais até o ano de 2024. Isso representa uma oferta de vagas bem superior a quantidade de profissionais habilitados, já que, segundo o próprio relatório, no Brasil são formados atualmente 46 mil pessoas com perfil tecnológico por ano.

Nesta proposta de projeto, destaca-se a metodologia desenvolvida para aplicação do curso, já que o ambiente onde ele será aplicado segue um rígido critério de

2 Reportagem O Globo. Disponível em: <https://oglobo.globo.com/brasil/cnj-revela-que-paistem-143-mil-mandados-de-prisao-em-aberto-22816955>. Acesso: 09 jan. 2019.

3 Relatório Basscom. Disponível em: https://brasscom.org.br/relatorio-setorial-de-tic-2019/. Acesso em 25 jul. 2019. 
segurança, não permitindo aos alunos portar sequer qualquer tipo de material escolar, como apostila, lápis ou papel fora do ambiente de aula.

A contribuição deste trabalho para a educação profissional está em utilizar, de forma criativa e lúdica, recursos da linguagem de programação Scratch para desenvolvimento do pensamento computacional como parte do processo de ressocialização destes alunos.

Este trabalho está organizado da seguinte maneira: Na Seção 2, estão presentes os aportes teóricos, abordando a relação entre educação e trabalho, a importância da educação como forma de superação do fenômeno da marginalidade e a ineficiência do sistema carcerário. Na Seção 3 é apresentada a estratégia desenvolvida. Na Seção 4 apresentam-se os resultados esperados e, na Seção 5, estão presentes as conclusões.

\section{Revisão de Literatura}

Karl Marx e Friedrich Engels afirmavam que os homens se distinguem dos animais logo que começam a produzir seus meios de existência. Para eles, é no trabalho que o homem produz sua própria vida material [Marx e Engels 1999].

Partindo do princípio de que educação e trabalho estão articulados [Kuenzer 1988], é preciso pensar meios que propiciem uma educação interessante, atrativa e que desperte nos alunos o gosto pelo aprender. Isso se justifica, principalmente, ao lembramos que a educação não está entre as prioridades dos internos, possivelmente porque eles aprenderam a conviver sem ela, já que para eles, escola é sinônimo de fracasso e frustração [de Maeyer 2006].

Considerando que o público alvo deste projeto vive à margem da sociedade, Saviani traz uma interessante contribuição ao relatar que a marginalidade é um desvio que não apenas pode, mas deve ser consertado. E que é papel da educação atuar na superação desse fenômeno, não apenas para combatê-lo, mas também para impedir seu reaparecimento [Saviani 2018].

Em [Julião 2007] também é possível observar que o simples encarceramento, quando desacompanhado de programas socioeducativo adequados, torna-se insuficiente para recuperar efetivamente uma quantidade significativa de apenados, gerando assim ônus para toda a sociedade, além de vir degenerando a condição de vida humana dessas pessoas. Por isso, Julião indaga se não é necessário reavaliar a cultura da prisão, que atualmente resulta na ideia de que a verdadeira ressocialização só pode ser alcançada quando o apenado vive o processo de privação de liberdade.

\subsection{Trabalhos Relacionados}

Há uma carência de trabalhos que se dispõem a estudar o desenvolvimento do pensamento computacional em pessoas que se encontram em privação de liberdade. Mas é possível encontrar alguns trabalhos que tem por objetivo desenvolver o pensamento computacional em crianças e jovens, além de trabalhos voltados a estudar os benefícios que podem ser obtidos através do estudo no cárcere.

Jeannette Wing (2006), responsável pela popularização do termo pensamento computacional na sociedade acadêmica, ressalta a importância dessa habilidade ser desenvolvida em todas as pessoas. Por isso, propõem que o pensamento computacional seja tratado como uma competência fundamental para qualquer estudante. 
No que se refere a utilização da ferramenta Scratch, as pesquisas realizadas por Oliveira (2014), Nunes (2018) e Da Costa (2018) mostram que foi possível obter resultados positivos utilizando essa plataforma no desenvolvimento do pensamento computacional e que ela é considerada atualmente uma das ferramentas de programação visual mais utilizadas para estimular o pensamento computacional.

Com relação a educação no carece, podemos destacar os trabalhos de Elionaldo F. Julião. Em sua pesquisa realizada para mensurar o impacto da educação e do trabalho como programa de reinserção social na política de execução penal do Rio de Janeiro (Julião 2010), foi possível apurar que a maioria dos internos prefere o estudo ao trabalho no cárcere, já que os internos enxergam no estudo uma perspectiva de futuro, principalmente quanto à reinserção social. A pesquisa em questão também mostrou que o estudo no cárcere diminui a probabilidade de reincidência em $39 \%$.

Em outra pesquisa que trata sobre a ressocialização através do estudo e do trabalho no sistema penitenciário brasileiro, o autor também nos mostra que podem existir diversos benefícios ao se trabalhar à educação no cárcere, como manter os internos ocupados de maneira proveitosa, melhorar a qualidade de vida no ambiente prisional, além da conquista de resultados considerados úteis, como aquisição de conhecimento, compreensão, mudança de atitudes, dentre outros comportamentos que perdurem além do cárcere (Julião 2009).

\section{Estratégia Desenvolvida}

Esse projeto de extensão está sendo elaborado com o aval da Secretaria de Estado da Justiça (SEJUS), devendo ser aplicado no segundo semestre de 2019 na Penitenciária Semiaberta de Vila Velha (PSVV), onde contará com um público formado por dez internos, maiores de 18 anos de idade, que estejam cumprindo pena no regime semiaberto, que possuem o ensino médio completo, ou em fase de conclusão, além de conhecimento básico em informática.

É importante destacar que os pré-requisitos estabelecidos para participar das oficinas foram formulados em conjunto com a Gerência de Educação da SEJUS, de maneira que as oficinas sejam formadas por alunos que possuem grandes expectativas de atuação no mercado de trabalho e que estão prestes a retomar o convívio social.

\subsection{Fase de Planejamento}

Para a fase de planejamento das oficinas, buscou-se nos trabalhos de Elionaldo Julião informações que ajudassem a definir características e preferências do público que é objeto deste estudo, de forma que as oficinas se tornem atraentes aos internos. Diante do relato de um preso da Unidade Plácido de Sá Carvalho, que afirmava "A grande realidade é que, acho que $90 \%$ do coletivo vive em função do futebol..." [Julião 2009 pg. 232], boa parte das atividades propostas nas oficinas terão como tema o futebol.

A preocupação em formular um material para as oficinas que desperte o gosto dos internos pelos estudos também se baseia na intenção de proporcionar aos alunos uma aprendizagem significativa, conceito central da teoria da aprendizagem do psicólogo norte-americano David Ausubel.

Quanto aos conceitos computacionais a serem explorados no decorrer das oficinas, estaremos nos valendo da experiência relatada em [de França e do Amaral 2013]. Nesse estudo, os pesquisadores também realizaram uma oficina com a ferramenta Scratch para estimular o desenvolvimento do Pensamento Computacional de 
um pequeno grupo de estudantes do Estado de Pernambuco. O resultado apurado na ocasião mostrou-se satisfatório em relação à aprendizagem de conteúdos de computação. Assim como ocorreu no referido estudo, a intenção desta pesquisa é que, no decorrer das oficinas, enquanto os alunos projetam soluções interativas utilizando o Scratch, seja feito uso de uma gama de conceitos computacionais comuns a diversas linguagens de programação, como sequencia, evento, paralelismo, loop, condicionais, operadores e armazenamento de dados. A esses conceitos, acrescentaremos ainda a compreensão de problemas e o fluxo de programação que envolve entrada, processamento, e saída. De forma paralela, e fazendo uso dos conceitos computacionais, estaremos buscando também trabalhar nos alunos as seguintes habilidades do pensamento computacional: decomposição, reconhecimento de padrão, abstração e pensamento algorítmico.

Com o objetivo de garantir que o produto preparado para as oficinas é compatível com o conhecimento prévio dos alunos, todo o material, antes de ser aplicado, será submetido a avaliação dos docentes que atuam na PSVV. Afinal, acreditamos ser de grande valia a opinião dos professores que já trabalham com boa parte dos potenciais alunos deste projeto de pesquisa.

\subsection{Fase de Ação}

Após o término da fase de planejamento, a fase da ação consistirá na aplicação das oficinas para os internos da PSVV. Para tanto, os recursos tecnológicos a serem utilizados são: computador ou notebook contendo o editor Scratch 3.0 desconectado para os alunos, que poderão utilizá-lo de forma individual ou em duplas, além de um projetor que será usado para exibição de vídeos e apresentações ilustrativas. A visão macro do conteúdo abordado nas oficinas pode ser visualizada nas Seções a seguir.

\subsubsection{Aula Introdutória}

Considerando que o curso será aplicado a um público muito específico, a primeira aula será destinada a conhecer um pouco melhor o perfil dos alunos, de forma que as estratégias para as oficinas sejam validadas ou reavaliada para as demais aulas.

Partindo do princípio que a educação não está entre as principais preocupações dos internos [de Maeyer 2006], como forma de motivar os alunos, nessa aula inicial apresentaremos um pouco do projeto The Last Mile, realizado em prisões da Califórnia para ensinar programação a pessoas privadas de liberdade. Além disso, para despertar a expectativa dos alunos quanto a possibilidade de ingresso no mercado de trabalho, serão apresentados alguns dados do relatório setorial da Brasscom, demonstrando a carência de profissionais com formação tecnológica no Brasil. Dessa forma, esperamos que os alunos compreendam que existe uma possibilidade real de transformação em suas vidas.

Por fim, a ferramenta Scratch será apresentada aos alunos.

\subsubsection{Oficina 01}

Nesta oficina serão apresentados aos alunos alguns blocos de comandos da ferramenta Scratch. Em seguida, utilizando os blocos já apresentados na oficina, eles serão estimulados a desenvolver sequências lógicas para atingir os objetivos propostos em aula. Um exemplo de tarefa proposta nesta oficina é a "cobrança de pênalti", que consiste em apresentar aos alunos a figura presente na tabela 1 e pedir a eles para produzir uma animação que atenda aos requisitos especificados nessa tabela: 


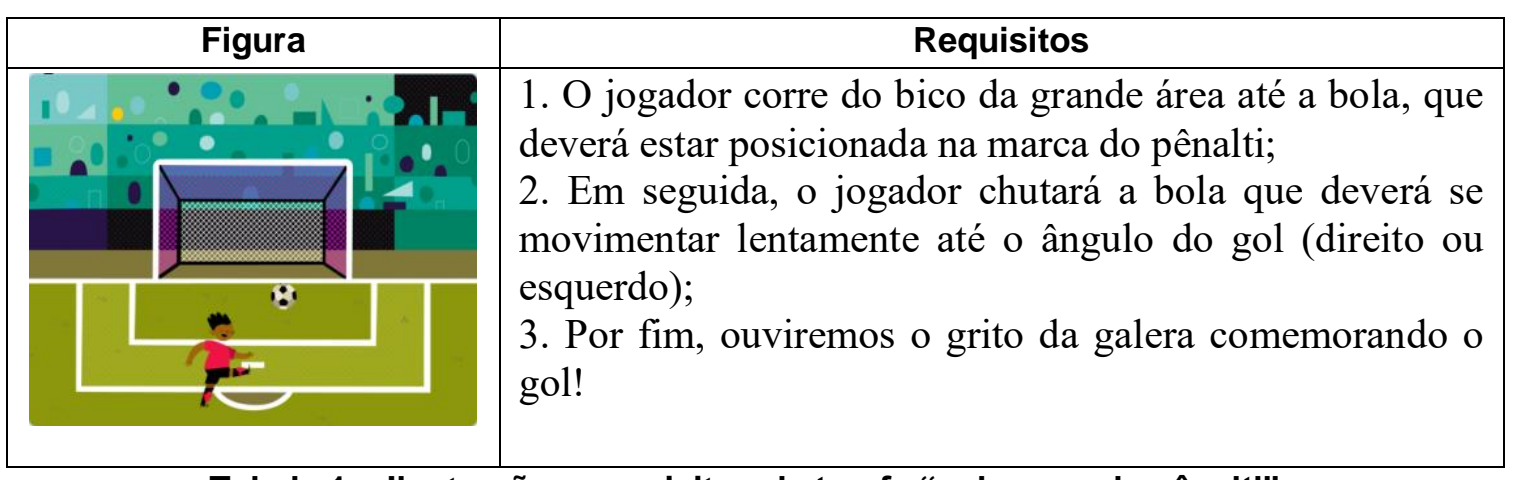

Tabela 1 - llustração e requisitos da tarefa "cobrança de pênalti"

Nesta tarefa, estaremos trabalhando com os alunos habilidades do pensamento computacional como decomposição e pensamento algorítmico, além de conceitos computacionais como sequência, evento e paralelismo.

A previsão é que esta oficina ocorra em duas aulas, totalizando quatro horas.

\subsubsection{Oficina 02}

A proposta desta oficina é que sejam trabalhados os conceitos de expressões lógicas (expressões cujo valor é verdadeiro ou falso) com os alunos. A previsão é que ela também ocorra em duas aulas, com duração de duas horas cada aula.

Um exemplo de tarefa proposta nesta oficina é o "labirinto do time favorito". Com base na figura da tabela 2, os alunos deverão criar um jogo onde a bola deve ser levada até o escudo do seu time favorito, conforme requisitos especificados abaixo.

\begin{tabular}{|c|c|}
\hline Figura & Requisitos \\
\hline & $\begin{array}{l}\text { 1. Ao começar o jogo, a bola deve estar posicionada no } \\
\text { local indicado e o aluno deverá utilizar as setas } \\
\text { direcionais do teclado para movê-la; } \\
\text { 2. Caso a bola saia do caminho branco traçado, o } \\
\text { jogador deverá receber um aviso, devendo a bola } \\
\text { retornar a posição anterior ao último movimento. Se a } \\
\text { falha ocorrer pela segunda vez, será exibido o aviso: } \\
\text { "Fim de jogo. Tente novamente"; } \\
\text { 3. Quando o jogador conseguir levar a bola ao seu time } \\
\text { favorito, ele será aplaudido e em seguida será tocado } \\
\text { o hino do clube. Porém, se a bola for levada ao escudo } \\
\text { de outro time, o jogador ouvirá uma sonora vaia. }\end{array}$ \\
\hline
\end{tabular}

Tabela 2 - Ilustração e requisitos da tarefa "labirinto do time favorito"

Nesta tarefa, estaremos trabalhando com os alunos habilidades do pensamento computacional como abstração, reconhecimento de padrão, decomposição e pensamento algorítmico, além de diversos conceitos computacionais como sequência, evento, paralelismo, loop, condicionais, operadores e armazenamento de dados.

\subsubsection{Oficina 03}

Nesta oficina os alunos serão estimulados a desenvolver pequenos programas que recebam uma informação do usuário (entrada). Diante dessa informação, determinadas ações deverão ser executadas (processamento) e, por fim, o usuário deverá receber um retorno do programa. A tabela 3 mostra um exemplo de tarefa proposta nesta oficina. 


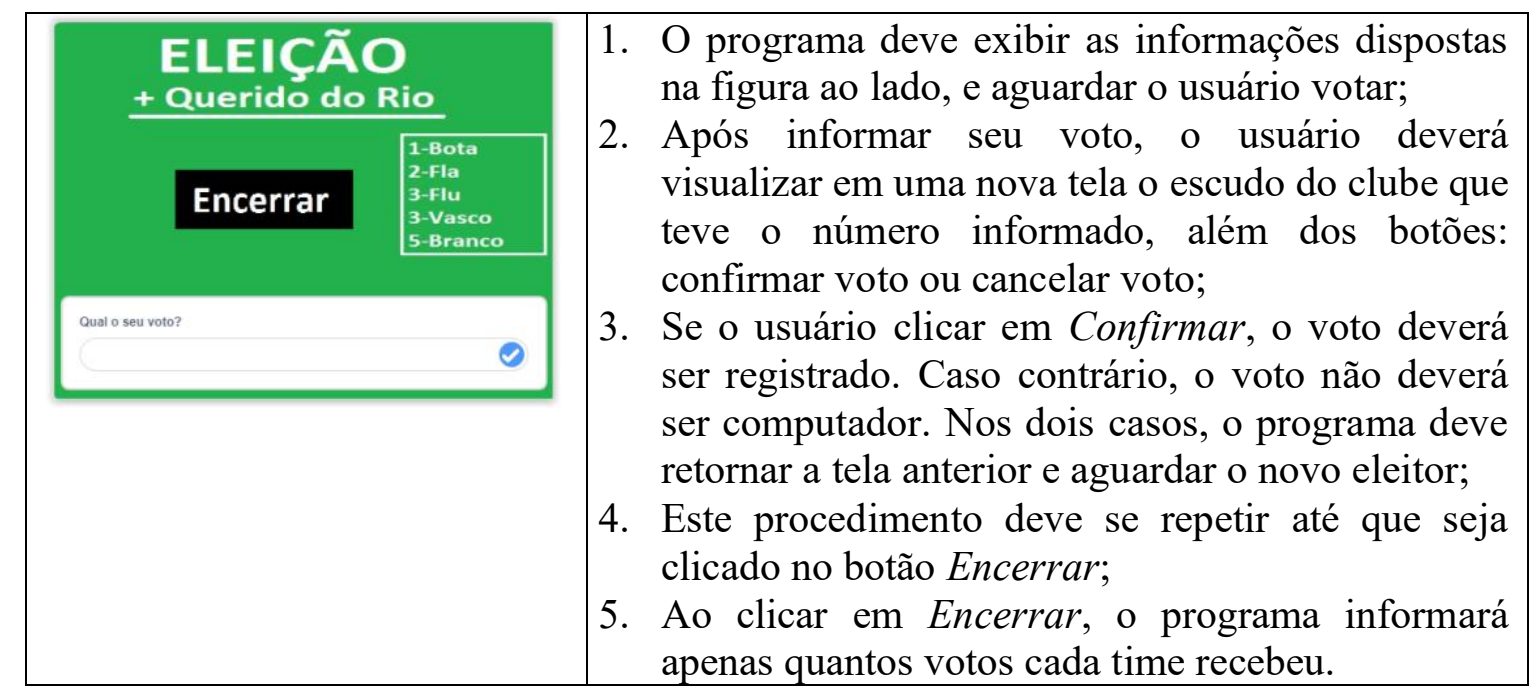

Tabela 3 - Ilustração e requisitos da tarefa "Eleição do time de futebol mais querido"

Nesta tarefa, estaremos trabalhando com os alunos habilidades do pensamento computacional como abstração, decomposição, reconhecimento de padrão e pensamento algorítmico, além de diversos conceitos computacionais como sequência, evento, paralelismo, loop e armazenamento de dados.

Considerando que o foco das oficinas não é a produção de imagens e áudios, sempre que houver a necessidade de utilizar recursos desta natureza que não estejam presentes no Scratch, os arquivos necessários serão disponibilizados em um diretório, onde poderão ser carregados para a ferramenta durante a realização das tarefas. A previsão é que esta oficina ocorra em três aulas, com duração de duas horas cada aula.

\subsubsection{Oficina 04}

Nesta oficina os alunos serão colocados diante de um problema qualquer, onde sua solução passe pela implementação de um programa. Para isso, eles precisarão compreender o problema apresentado e desenvolver a solução no Scratch. Diferente das outras oficinas, neste caso não haverá instruções de como implementar o programa.

Um exemplo de tarefa que será proposta nesta oficina é o desenvolvimento de um programa que mostre ao usuário quais são as duas cartas que devem ser escolhidas por ele no jogo conhecido como "Samba 10".

Para realização desta tarefa, os alunos receberão apenas a explicação de como funciona o jogo, e em seguida deverão implementar a solução.

O jogo em questão funciona da seguinte forma: o jogador recebe 03 cartas numéricas que variam de 0 a 15 . Seu objetivo é escolher duas dessas três cartas e realizar a operação de soma ou subtração entre elas com o intuito de alcançar o resultado 10 , ou chegar o mais próximo possível.

Espera-se da solução desenvolvida pelos alunos que, após o usuário informar quais são as três cartas recebidas, o programa informe as duas cartas que devem ser escolhidas, bem como a operação a ser utilizada (soma ou subtração). Por exemplo, se o jogador tem nas mãos as cartas 9, 2 e 4, o programa deve indicar que ele escolha as cartas 9 e 2 e realize a operação de soma, já que esta é a combinação que mais se aproximará do número 10.

Para que o conceito do jogo fique mais claro, os alunos serão convidados a jogar 
uma partida com as cartas que serão disponibilizadas durante a aula. A previsão é que esta oficina ocorra em duas aulas, totalizando quatro horas.

É válido ainda destacar que, com o objetivo de estimular os alunos a desenvolver o pensamento computacional também fora do ambiente de sala de aula, na parte final de cada aula sempre será apresentado um problema/tarefa aos alunos, que ficarão responsáveis em desenvolver o pensamento sobre como o problema apresentado poderá ser resolvido, enquanto estiverem fora da sala de aula. Assim, na aula seguinte, os alunos deverão utilizar os conceitos aprendidos na aula anterior e implementar a solução pensada durante esse intervalo entre as aulas.

\subsection{Fases Descrição e Avaliação}

As fases de descrição e avaliação ocorrerão paralelamente e serão realizadas com base na observação do pesquisador e análise dos blocos de comando desenvolvidos pelos alunos durante a execução das tarefas propostas em sala de aula.

Esta etapa será devidamente documentada ao término de cada atividade proposta em sala de aula. Portanto, para fase de descrição estaremos desenvolvendo um formulário próprio com o objetivo de que o pesquisador possa pontuar informações relevantes que ajudem a melhorar o conteúdo abordado nas oficinas.

Com a intenção de buscar as melhores práticas para avaliação do pensamento computacional, estaremos utilizando a contribuição da revisão sistêmica realizada em [Avila et al. 2017]. Nessa pesquisa, onde os autores se propõem a realizar a avaliação do Pensamento Computacional em diferentes cenários de ensino, verificou-se que a maioria dos artigos analisados entre 2011 e 2016 realizaram avaliações por meio de ferramentas desenvolvidas pelos próprios pesquisadores, tais como: pré e pósquestionários de opinião, pré e pós-testes de conhecimento, além de observações e análise do material produzido pelos alunos. Em alguns trabalhos, foi possível observar ainda a utilização da ferramenta $D r$. Scratch. Trata-se de uma ferramenta web que permite a avaliação automática dos programas desenvolvidos na ferramenta Scratch, fornecendo ainda feedback ao desenvolvedor, com o objetivo de aperfeiçoar o desenvolvimento do pensamento computacional [Moreno-León et al. 2015].

Utilizando a ferramenta Dr. Scratch e analisando os blocos de comandos montados pelos alunos, será possível averiguar a eficácia da metodologia adotada e também mensurar o nível de aprendizado dos internos. Assim, acreditamos que será possível pontuar informações relevantes para melhorar o conteúdo abordado nas oficinas, além de monitorar o nível de aprendizado dos alunos.

\section{Resultados esperados}

Considerando as premissas de educação e profissionalização da pessoa reclusa como possíveis condições para o seu (re) ingresso no mundo do trabalho e partindo do princípio que o sistema de reclusão tem por objetivo não somente a punição do infrator, mas também fornecer meios para sua ressocialização, espera-se que este projeto possa contribuir no processo de retorno dos internos ao convívio social a partir do desenvolvimento do pensamento computacional e do ensino de conceitos iniciais de programação de computadores.

O principal fruto deste trabalho está no desenvolvimento de novas perspectivas na vida das pessoas que se encontram em privação de liberdade, de forma que estes sujeitos possam enxergar que, através do desenvolvimento do pensamento 
computacional e da programação, é possível trilhar um caminho lícito, longe dos furtos, roubos, e tráfico, já que essas são as principais causas do encarceramento no país.

Partindo do princípio que o foco deste trabalho é, literalmente, desenvolver o pensamento computacional da pessoa em condição de confinamento, também existe a expectativa de que o ato de pensar de maneira criativa, iniciado em sala de aula, possa estender-se para o ambiente do cárcere, fazendo com que o interno mantenha sua mente voltada para a solução criativa dos problemas e exercícios vivenciados no ambiente de estudos, mantendo seus pensamentos e intenções livres de atos ilícitos.

Espera-se ainda que, ao final do projeto, seja detectado o interesse do apenado em dar continuidade nos estudos, o que permitirá sua evolução para capacitações que abordem em mais detalhes o desenvolvimento de soluções computacionais.

Diante dessa expectativa, esperamos que as autoridades competentes possam rever algumas políticas de forma a garantir que as unidades prisionais disponham de uma infraestrutura tecnológica mínima, capaz de permitir que os presos possam não somente capacitar-se, mas também evoluir dos estudos para o trabalho, desenvolvendo assim soluções computacionais de dentro do próprio cárcere. Isto fará com que o apenado possa garantir o seu próprio sustento ainda no ambiente de reclusão, desonerando o Estado desta tarefa, que por sua vez poderia direcionar estes recursos para investimentos que beneficiariam toda a sociedade.

\section{Conclusão}

A proposta exposta neste trabalho trata da aplicação de um curso, em formato de oficinas, a ser realizado Penitenciária Semiaberta de Vila Velha (PSVV), com o objetivo de desenvolver o pensamento computacional dos internos, trazendo assim novas perspectivas sociais e profissionais aos alunos.

As pesquisas analisadas até o momento mostram que o estudo no cárcere apresenta números consideráveis quanto a diminuição na taxa de reincidência criminal e que é possível desenvolver nos alunos o pensamento computacional utilizando a linguagem de programação Scracth. Porém, sua aplicação em um ambiente prisional, onde existem rígidas regras segurança, ainda é um tema pouco explorado na ciência.

Por fim, dando continuidade ao estudo proposto, pretende-se seguir com as etapas da estratégia desenvolvida, aplicando as oficinas junto aos alunos da PSVV, avaliar os resultados obtidos, fazer possíveis ajustes e apontar possíveis melhorias.

\section{Referências}

Avila, C., Cavalheiro, S., Bordini, A., Marques, M., Cardoso, M., \& Feijo, G. (2017, October). Metodologias de Avaliação do Pensamento Computacional: uma revisão sistemática. In Brazilian Symposium on Computers in Education (Simpósio Brasileiro de Informática na Educação-SBIE) (Vol. 28, No. 1, p. 113).

de França, R. S., \& do Amaral, H. J. C. (2013). Proposta metodológica de ensino e avaliação para o desenvolvimento do pensamento computacional com o uso do scratch. In Anais do Workshop de Informática na Escola (Vol. 1, No. 1, p. 179).

de Maeyer, M. (2006). NA PRISÃO EXISTE A PERSPECTIVA DA EDUCAÇÃO AO LONGO DA VIDA?. Alfabetização, 17. 
Fernandes Julião, E. (2010). O impacto da educação e do trabalho como programas de reinserção social na política de execução penal do Rio de Janeiro. Revista Brasileira de Educação, 15(45).

Julião, E. F. (2007). Educação para jovens e adultos privados de liberdade: desafios para a política de reinserção social. Salto para o futuro, boletim, 6 .

Julião, E. F. (2009). A ressocialização através do estudo e do trabalho no sistema penitenciário brasileiro. Rio de Janeiro.

Kuenzer, A. (2013). Ensino do $1^{\circ}$ grau: o trabalho como principio educativo. Cadernos de Pesquisa, (68), 108.

Marx, K., \& Engels, F. (2015). A ideologia alemã: crítica da mais recente filosofia alemã em seus representantes Feuerbach, B. Bauer e Stirner, e do socialismo alemão em seus diferentes profetas. Boitempo editorial.

Moreno-León, J., Robles, G., \& Román-González, M. (2015). Dr. Scratch: Automatic analysis of scratch projects to assess and foster computational thinking. RED. Revista de Educación a Distancia, (46), 1-23

Nunes, Marina Macedo et al. Uso da lógica de programação para potencializar o pensamento criativo em crianças do ensino básico. Anais dos Workshops do Congresso Brasileiro de Informática na Educação. Fortaleza, v. 1, n. 7. 2018.

Oliveira, MLS de et al. Ensino de lógica de programação no ensino fundamental utilizando o Scratch: um relato de experiência. XXXIV Congresso da SBC-XXII Workshop de Ensino de Computação. Brasília. v. 1, n. 34, 2014.

Saviani, D. (2018). Escola e democracia. Autores Associados.

Wing, Jeannette. Pensamento computacional: um conjunto de atitudes e habilidades que todos, não só cientistas da computação, ficaram ansiosos para aprender e usar. Revista Brasileira de Ensino de Ciência e Tecnologia. Curitiba, v. 9, n. 2, 2016. 